\title{
Schedule Matters: Understanding the Relationship between Schedule Delays and Costs on Overruns
}

\author{
Walt Majerowicz \\ NASA Goddard Space Flight Center \\ 8800 Greenbelt Rd., Code 400 \\ Greenbelt, Maryland 20771 \\ (443) 883-5267 \\ walt.majerowicz@nasa.gov
}

\author{
Stephen A. Shinn \\ NASA Goddard Space Flight Center \\ 8800 Greenbelt Rd., Code 400 \\ Greenbelt, Maryland 20771 \\ (301) 286-5894 \\ stephen.a.shinn@nasa.gov
}

\begin{abstract}
This paper examines the relationship between schedule delays and cost overruns on complex projects. It is generally accepted by many project practitioners that cost overruns are directly related to schedule delays. But what does "directly related to" actually mean? Some reasons or root causes for schedule delays and associated cost overruns are obvious, if only in hindsight. For example, unrealistic estimates, supply chain difficulties, insufficient schedule margin, technical problems, scope changes, or the occurrence of risk events can negatively impact schedule performance. Other factors driving schedule delays and cost overruns may be less obvious and more difficult to quantify. Examples of these less obvious factors include project complexity, flawed estimating assumptions, over-optimism, political factors, "black swan" events, or even poor leadership and communication. Indeed, is it even possible the schedule itself could be a source of delay and subsequent cost overrun? Through literature review, surveys of project practitioners, and the authors' own experience on NASA programs and projects, the authors will categorize and examine the various factors affecting the relationship between project schedule delays and cost growth. The authors will also propose some ideas for organizations to consider to help create an awareness of the factors which could cause or influence schedule delays and associated cost growth on complex projects.
\end{abstract}

\section{TABLE OF CONTENTS}

1. INTRODUCTION. 1

2. SCHEdUle Delay PERSPECTIVES................................ 2

3. INTERDEPENDENCY OF SCHEDULE AND COST............... 3

4. Root Causes of SCHedule Delays AND CoST OVERRUNS 4

5. CONCLUSIONS AND RECOMMENDATIONS.................... 6 REFERENCES . BIOGRAPHY 8

\section{INTRODUCTION}

Cost overruns on government programs frequently attract significant attention from federal agency executive leadership, the Government Accountability Office, Congress, the White House, and even the public at large. One could argue that in the face of shrinking budgets, some federal agencies are incentivized to unrealistically minimize cost and exaggerate maximum technical performance. The optimistic assumptions associated with the minimum cost/maximum performance precept become integral to program baselines which, lead to cost overruns. As more desirable programs chase decreased Agency funding, the incentive to underestimate program cost increases. Later, when funding shortfalls actually happen, inefficient practices of deferring work, cutting scope and capability, or shifting funding between projects occurs. These shortsighted adjustments, of course, continue to exacerbate cost growth [1].

Closely aligned with an unrealistic program cost position may be an equally unrealistic, success-oriented schedule. In fact, in the operational reality of project formulation and implementation, a sure-fire path to a cost overrun is an unachievable schedule. However, the relationship between schedule delays and cost overruns is multifaceted. Does a schedule delay always translate into a cost overrun? Are there other aspects of the schedule that contribute to cost overruns, even though a delay is not experienced? Can most cost overruns be traced to root causes in the schedule execution, or are there other explanations? While the authors could not locate a specific source, the view that " 80 to 90 percent of cost overruns are due to schedule" is often discussed among project practitioners. While it may be difficult to quantitatively support or refute this view, perhaps an examination of the anecdotal, empirical, and observed data and experiences can shed more light on this claim.

The National Aeronautics and Space Administration (NASA) has developed and managed some of the world's most complex systems and projects. Yet, along with that scientific success, the Agency has also experienced significant cost overruns and schedule delays. Within NASA, the Goddard Space Flight Center (GSFC) has more than a 50-year history of managing complex, scientific projects including weather satellites, Earth observing satellites, and space communication systems, along with solar, planetary and deep space observatories. GSFC's projects are technically complicated and programmatically complex, often integrating in-house work with effort from industry contractors, international partners, and other NASA centers.

In light of previous schedule delays and cost overruns on some of these projects, GSFC has instituted a number of organizational, technical, and project management initiatives 
to improve performance of cost and schedule. The Business Change Initiative (BCI) resulted in over 100 changes in the areas of scheduling, Earned Value Management (EVM), cost estimating, management reporting, and risk management to enhance project teams' ability to plan and control projects to better achieve their cost and schedule performance targets.

Some of these BCI changes are included in the recommendations at the end of this paper. Similarly, GSFC's project experiences along with insights from other project practitioners provide a fresh perspective on the relationship between cost overruns and schedule delays.

\section{Schedule Delay Perspectives}

"Time is money," Benjamin Franklin observed long ago. The project management equivalent to Dr. Franklin's observation for today's project practitioner might be "as the schedule goes, so goes the cost." Therefore, avoiding or minimizing schedule growth is important to projects because it saves money that might be put to more effective use elsewhere, besides funding cost growth and overruns caused by these delays. But what is the nature of schedule delays and overruns in today's complex project environment like that at GSFC?

Table 1 summarizes the authors' perspective on the major themes within which schedule delays and overruns can be characterized.

First, insufficient scope planning occurs when work scope is incorrectly included or excluded from the project schedule.
Since the work is not in the baseline plan, it eventually "creeps" back into the schedule forecast and estimate-tocomplete translating into schedule delays and additional cost growth. Likewise, lack of effective change management from the initial evaluation of a potential technical or programmatic change through to its successful implementation into the project can lead to time delays, if not coordinated properly. Of course, inadequate requirements definition can adversely impact scope planning and change management processes too, ultimately leading to schedule delays and cost overruns. Therefore, proper requirements management is essential for avoiding schedule and cost problems to begin with.

Another recurring theme concerns the constraints projects create by preparing success-oriented estimates of activity durations. A success-oriented schedule means everything has to go exactly right and is estimated to complete the activity as planned - not a very likely outcome for the majority of tasks, given the uncertainty associated with duration estimates. Nevertheless, projects can leverage techniques such as three-point estimates and schedule margin planning to offset inefficiency to some degree.

Next, at organizations such as GSFC, projects are complex and adapting to new technologies, or troubleshooting difficulties inherent in new technologies, can mean trouble for the schedule since challenges cannot be fully understood at the beginning of the project life cycle and difficulties may occur later [2]. From a schedule development perspective, programmatic complexity is expressed, in part, through the schedule logic within the Integrated Master Schedule (IMS).

Table 1. Schedule Overrun/Delay Themes

\begin{tabular}{|l|l|l|}
\hline \multicolumn{1}{|c|}{ Schedule Overrun/Delay Themes } & \multicolumn{1}{|c|}{$\begin{array}{c}\text { Affected Project Management } \\
\text { Processes }\end{array}$} & \multicolumn{1}{c|}{ Impact/Outcome } \\
\hline $\begin{array}{l}\text { Insufficient scope planning; ineffective } \\
\text { change management; inadequate } \\
\text { requirements definition }\end{array}$ & $\begin{array}{l}\text { Activity definition; baseline control; } \\
\text { requirements management }\end{array}$ & $\begin{array}{l}\text { Missing or under-scoped planning } \\
\text { packages, work packages, and } \\
\text { activities }\end{array}$ \\
\hline Success-oriented estimates & Activity duration estimating & $\begin{array}{l}\text { Overoptimistic planning package, work } \\
\text { package, and activity duration } \\
\text { estimates }\end{array}$ \\
\hline Project complexity & Activity sequencing & $\begin{array}{l}\text { Missing or incorrectly defined schedule } \\
\text { logic and dependencies; merge bias }\end{array}$ \\
\hline Inadequate risk assessment & Probabilistic schedule risk analysis & $\begin{array}{l}\text { Overloaded risks; underestimated risk } \\
\text { probabilities and impacts }\end{array}$ \\
\hline Technical/programmatic problems & $\begin{array}{l}\text { Risk management; schedule margin } \\
\text { planning }\end{array}$ & $\begin{array}{l}\text { Performance inefficiency; schedule } \\
\text { margin erosion; missed milestones }\end{array}$ \\
\hline $\begin{array}{l}\text { Other (leadership, communication, } \\
\text { supplier, process, etc. problems) }\end{array}$ & All & $\begin{array}{l}\text { Performance inefficiency; schedule } \\
\text { margin erosion; missed milestones }\end{array}$ \\
\hline "Black Swan" events & $\begin{array}{l}\text { Recovery planning, continuous } \\
\text { planning }\end{array}$ & $\begin{array}{l}\text { Major schedule impact; major replan; } \\
\text { project termination }\end{array}$ \\
\hline
\end{tabular}


When a dependency for a deliverable is overlooked or linked incorrectly in the IMS, it could result in a significant schedule impact once the problem is detected and resolved. Several years ago, a component delivery from a GSFC contractor was incorrectly linked to its point of need in the spacecraft integration and test flow. Once the problem was identified and the correct dependency established, it translated into a potential multi-month schedule delay. Significant time and cost on the part of the project team and contractor was invested (including the allocation of some schedule margin) to work around the problem, which was eventually solved. Even more challenging from a project complexity standpoint is when multiple parallel schedule paths, each with their own variability or uncertainty, converge at a single activity or milestone. This "merge bias" effect reduces the probability of starting or finishing the merged task on time [3].

Similarly, projects may not perform adequate assessments of risk. In fact, risks could be overlooked, underestimated in terms of probability or impact, or even ignored. If these risks occur, projects may not be fully prepared to recover from their impacts - especially if the risks occur late in the project life cycle. Another theme concerns the occurrence of actual problems and their impact on project performance. The occurrence of technical or programmatic problems such as parts shortages, test failures, or resource shortfalls result in performance inefficiencies, rework, or troubleshooting that delays the schedule and increases cost.

Too often intangible factors such as inexperienced project leadership, lack of documented processes, complicated organizational structures, or strained interpersonal relations between team members can contribute to schedule delays as well. These occurrences may accumulate and decrease efficiency in performing the project work, impacting the schedule at the task level.

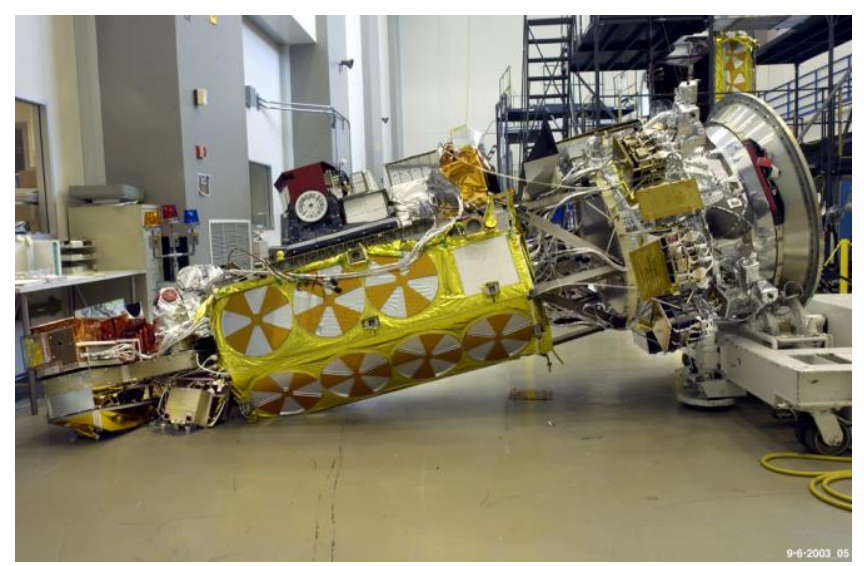

Figure 1. NOAA-N' Mishap Impacted Launch Schedule

Finally, rare and highly improbable "black swan" events may occur that impact the schedule. These events are truly "showstoppers" that often result in a termination of the project before its product can operate or produce results. In other cases, the occurrence of "black swan" events necessitate a major restructuring of a project. For example, in September 2003, the NOAA-N' satellite was badly damaged during integration at the Lockheed Martin Space Systems factory in Sunnyvale, CA. As the integration and test team was turning the satellite into a horizontal position, it fell to the floor, as shown in Figure 1 [4].

\section{INTERDEPENDENCY OF SCHEDULE AND COST}

Many large organizations have articulated that schedule and cost are very closely correlated. Observations, studies, and research into cost and schedule related topics have been performed by organizations such as NASA, the United States Department of Defense, Booz Allen Hamilton, and The Aerospace Corporation. These studies have repeatedly found close correlations to schedule delays and cost overruns, although correlation does not necessarily mean causality. Therefore, while we can observe that both cost and schedule may move in the same direction (i.e., overrun), other factors may be responsible for driving the schedule delay which, in turn, contributes to the cost growth.

When cost growth is identified in a project, schedule growth is usually experienced and vice versa. Likewise, when project risks become problems, they will often result in schedule delays and cost overruns as well. As Mike Cole pointed out in his 2012 NASA Project Management (PM) Challenge presentation, the various aspects of project management can only be effectively managed and mitigated if the schedule, cost, and risk planning and execution are fully integrated [5].

NASA and The Aerospace Corporation conducted a study, summarized in a NASA PM Challenge 2010 presentation by C. Freaner, B. Bitten, and D. Emmons, to characterize the properties of cost growth and schedule delays as they related to the phase of the project as well as to technical resource growth. While the study of 20 of NASA's recently completed science missions did not investigate the causes of schedule delays and cost overruns, it revealed an interesting relationship between cost and schedule. The study found a correlation between cost and schedule growth of these projects of $\mathrm{R}^{2}=0.61$, as shown in Figure 2 [6]. According to Bitten, the "general rule of thumb is that for every percent of schedule growth, there is an equal or greater percent of cost growth." He further stated that "almost all [cost overruns] started with schedule delays that lead to cost growth" [7].

Similarly, an earlier Aerospace Corporation study of 40 NASA science missions revealed that a 10 percent increase in schedule correlates to a 12 percent increase in cost [8].

In general, a schedule delay means that the cost will increase. Since most aspects of the cost estimate can be impacted by speeding up or slowing down the schedule, the relationship between cost and schedule appears to be highly correlated intuitively. However, some factors affect cost without an accompanying impact to schedule, such as labor or indirect rate changes. Inflation and changes in the estimated cost due 
to negotiations are two more factors that have little impact on schedule. Additionally, while implementing schedule workarounds may avoid or reduce the impact of schedule delays, they would also likely increase the project cost or reduce reserves. Fuel and materials cost increases, as well as the cost of implementing risk mitigation plans may also increase project costs without delaying the schedule.

Conversely, schedule delays do not always result in cost overruns. A well-integrated cost and schedule plan with sufficient margin in funds and time can accommodate some schedule delays without impacting the final cost, though cost reserves may be impacted. A prime example of this situation overruns or are these delays just a result of other root causes? If we define a root cause as the initiating condition that directly leads to an undesirable outcome which could have been avoided by some form of intervention, then a schedule slip cannot be a root cause [9]. The schedule slip is akin to the fire that burned down a vacant house. The fire is directly related to the burned down house, but what caused the fire in the first place?

When gathering research for this paper, the authors posed this question to various project practitioners: are schedule delays the root cause of cost overruns? Responses to this question were interesting.

\section{Correlation Between Cost and Schedule Growth Indicates that Schedule Growth Has Strong Influence on Cost Growth}

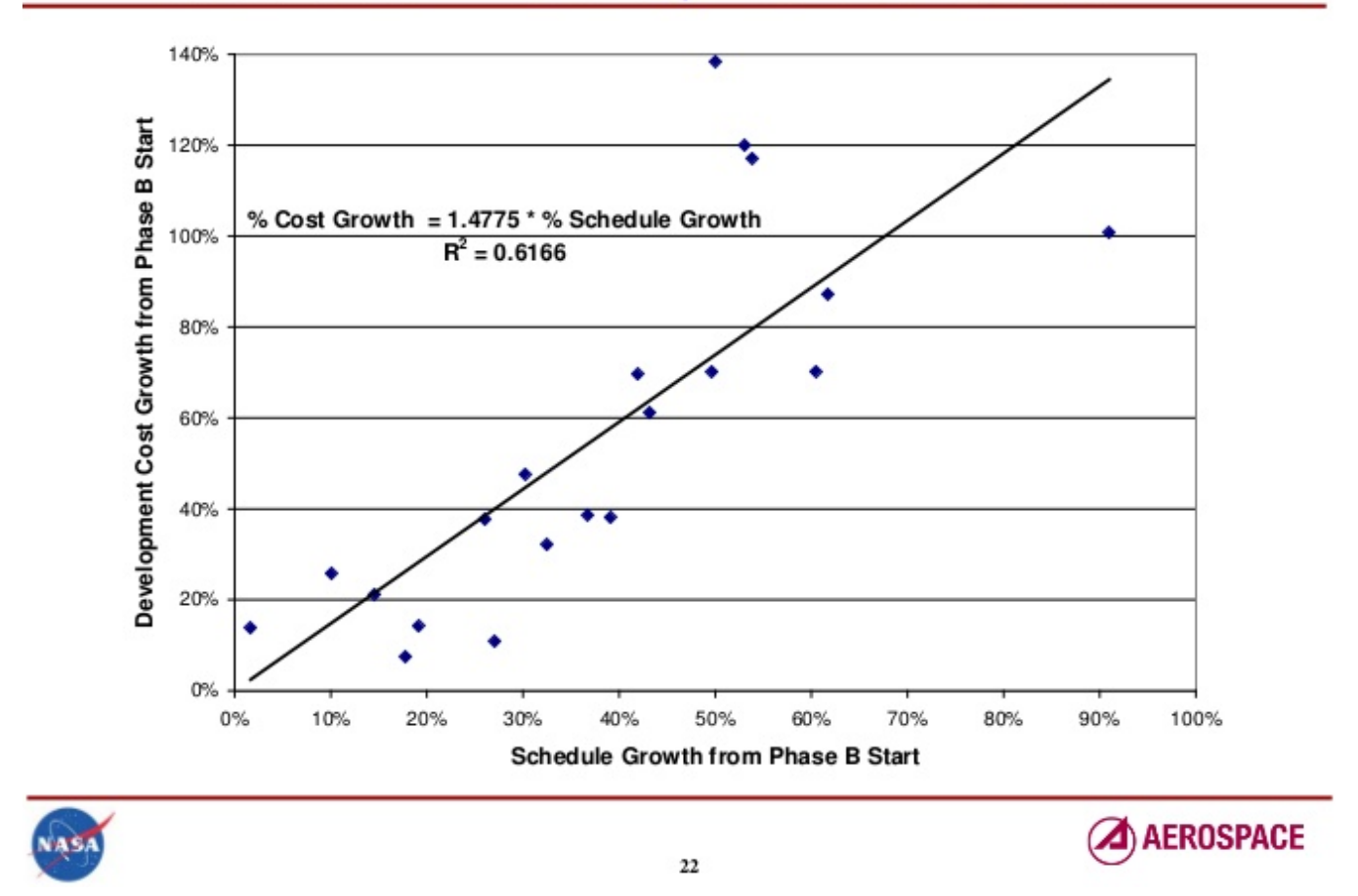

Figure 2. Correlation between Cost and Schedule for 20 NASA Projects

was experienced on a previous NASA GSFC project. A funding shortfall for the fiscal year forced the project to delay the procurement of long lead parts for a major subsystem. Through careful schedule workarounds and negotiation of waivers to incrementally fund fixed price contracts, the project was able to sustain the schedule slip without an increase in the overall funds required by the project. The schedule slip was mitigated avoiding a cost overrun.

\section{Root Causes of Schedule Delays AND COST OVERruns}

Many experienced project practitioners would agree that schedule slips and cost overruns are highly correlated because the same root causes impact both cost and schedule. But, are schedule slips themselves root causes of cost
According to one project practitioner, "that's a bit like asking which came first, the chicken or the egg! I've seen plenty of research that shows cost and schedule overruns are correlated, but correlation does not mean causality. In most cases, I think both cost and schedule overruns are caused by another factor, like underestimating the scope of work, overestimating the productivity of the people doing the work, underbidding the job, and many more. Schedule growth is a symptom of these problems, but not a root cause."

Another practitioner agreed with the position above stating that "I would probe the reason or reasons behind the schedule delay. I think you would find that the schedule delay isn't the root cause but rather a related impact."

Still another respondent put it succinctly, "a high correlation between cost and schedule [leads me] to conclude that we 
should assign the same factors to cost growth and schedule growth (and vice versa)."

A recent study, performed by the Joint Space Cost Council, dated April 15, 2015, points to poorly defined scope and planning to funding profiles as the most common reasons for cost impacts in Earned Value Management Systems [10].

This finding is consistent with a 2012 NASA Inspector General Audit Report [11] which concluded that NASA's cost, schedule, and performance failures could be traced to four main challenges:

(1) Over optimism, which is pervasive in the NASA culture. This prevents project teams from estimating realistic costs, schedules, and technical risks at the project outset.

(2) Underestimating technical complexity, whether intentionally or through lack of adequate scope definition. The resulting ill-defined scope increases the cost and schedule.

(3) Funding instability. Continuous lack of stable funding profiles and solid knowledge of funding for projects force project managers to make decisions that are often inefficient, resulting in cost and schedule growth.

(4) Limited opportunities for project manager development.
Without a broad-based project organization which provides learning and growth opportunities at the project team level, project managers are sometimes given jobs for which they are not adequately prepared. Learning project management "on the job" can allow for mistakes and inefficiencies in the decision making process which in turn, causes cost and schedule growth.

NASA's Advisory Council also acknowledged many other reasons for cost and schedule growth in their 2009 report, as represented in Table 2. This table shows that inadequate definition and over optimistic estimates have been recognized for most of NASA's history. In the 1990s, as the Federal budget became tighter, funding stability was introduced as another cause of cost growth. Likewise, in the same timeframe, as in-house technical opportunities disappeared, the lack of adequate project management training opportunities also became an issue for NASA.

These various studies and observations support the idea that schedule delays and cost overruns are closely related and that while some factors and causes impact both cost and schedule, often problems will first manifest themselves in a time delay which, in turn, leads to cost growth. Additionally, there is one characteristic, unique to logic-based project schedules, which may actually create the conditions that directly lead to schedule delays on complex projects: merge bias.

Table 2. NASA Advisory Council Meeting: Reasons for Cost Growth in NASA Projects

\begin{tabular}{|c|c|c|c|c|}
\hline Cost Growth Reasons & 1970s & 1980s & 1990s & $2000 \mathrm{~s}$ \\
\hline $\begin{array}{l}\text { Inadequate Definitions Prior to Agency Budget Decision and to } \\
\text { External Commitments }\end{array}$ & $\mathrm{X}$ & $\mathrm{X}$ & $\mathrm{X}$ & $\mathrm{X}$ \\
\hline Optimistic Cost Estimates/Estimating Errors & $\mathrm{X}$ & $\mathrm{X}$ & $\mathrm{X}$ & $\mathrm{X}$ \\
\hline Inability to Execute Initial Schedule Baseline & $\mathrm{X}$ & $\mathrm{X}$ & $\mathrm{X}$ & $\mathrm{X}$ \\
\hline Inadequate Risk Assessments & $\mathrm{X}$ & $\mathrm{X}$ & $\mathrm{X}$ & $\mathrm{X}$ \\
\hline Higher Technical Complexity of Projects than Anticipated & $\mathrm{X}$ & $\mathrm{X}$ & $\mathrm{X}$ & $\mathrm{X}$ \\
\hline Changes in Scope (Design/Content) & $\mathrm{X}$ & $\mathrm{X}$ & $\mathrm{X}$ & $\mathrm{X}$ \\
\hline Inadequate Assessment of Impacts of Schedule Changes on Cost & & $\mathrm{X}$ & $\mathrm{X}$ & $\mathrm{X}$ \\
\hline Annual Funding Instability & & & $\mathrm{X}$ & $\mathrm{X}$ \\
\hline Eroding In-House Technical Expertise & & & $\mathrm{X}$ & $\mathrm{X}$ \\
\hline Poor Tracking of Contractor Requirements Against Plans & & & $\mathrm{X}$ & $\mathrm{X}$ \\
\hline Launch Vehicle & & & $\mathrm{X}$ & \\
\hline Reserve Position Adequacy & & $\mathrm{X}$ & & $\mathrm{X}$ \\
\hline Lack of Probabilistic Estimating & & $\mathrm{X}$ & & $\mathrm{X}$ \\
\hline "Go As You Can Afford" Approach & & & & $\mathrm{X}$ \\
\hline $\begin{array}{l}\text { Lack of Formal Document for Recording Key Technical, Schedule, and } \\
\text { Programmatic Assumptions }\end{array}$ & & & & $\mathrm{X}$ \\
\hline
\end{tabular}


As introduced earlier and referenced in Table 1, merge bias is the impact of having two or more parallel paths of activities, each with its own variability or uncertainty, merge into one milestone or other activity. This somewhat arcane concept is not well understood by project teams, yet its effect can have serious consequences for the project schedule [12]. Figure 3 illustrates merge bias.

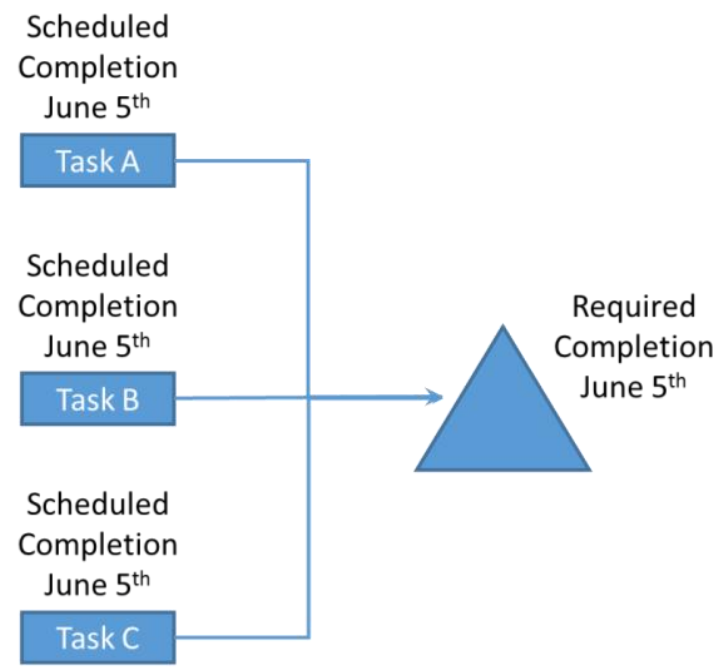

If each task has a completion probability of .70, what is the probability that the June $5^{\text {th }}$ delivery will occur on time?

\section{Figure 3. Merge Bias Illustrated}

Consider the three independent, parallel activities which feed into the delivery milestone in Figure 3. Each has been scheduled to finish by June 5 so the delivery milestone of June 5 can be met. However, each task has a completion probability of .70 - in other words, each has a 70 percent probability of finishing by June 5 . Since each of the three tasks are required to successfully complete the June 5 delivery milestone, the product of these task's completion probabilities is the true probability of delivering by June $5 . .70 \times .70 \times .70=.34$. Merge bias drives the probability of delivering by June 5 as planned down to 34 percent! Simply put, the more paths that merge into another task or milestone, the more there is to go wrong which could delay the schedule.

Now consider complex projects such as the spacecraft and ground system development projects at GSFC with hundreds or even thousands of interdependencies between tasks. The sheer complexity of the schedule is quantified in the merge bias phenomena. Merge bias is not a metric reported at program reviews. In the authors' experience it has never been addressed or discussed during the project planning process, at risk reviews, schedule status meetings, or during Integrated Baseline Reviews. On rare occasions it has been discussed by programmatic analysts as part of the independent review board process on some projects at NASA. Perhaps the project planning and control process would benefit from additional insight into the merge bias phenomena.

Schedule logic is a primary way to characterize project complexity. While missing or faulty logic is a concern, overlooking the effect of merge bias could be considered a cause of schedule delays if not fully considered in the risk assessment and schedule margin planning processes.

\section{CONCLUSIONS AND RECOMMENDATIONS}

Organizations and project teams that recognize the factors that may contribute to, or cause, schedule delays and cost growth, and takes steps to reduce or eliminate their impact, are better positioned for project success. Indeed, some of these factors are clearly understood such as discrete risk events, while others are more subtle such as team conflict internally or with a supplier. Process-based challenges in areas such as overoptimistic planning and estimating are well known, but more esoteric concepts such as merge bias can impact the project schedule and ultimately project cost if not recognized, understood, and addressed.

Are "80 to 90 percent of cost overruns due to schedule," as suggested previously? If we define "due to" as meaning related to or associated with, it does appear that the majority of cost overruns do trace back to, or in some way involve, the project schedule. This relationship of schedule to cost can be as direct as a test failure and its associated rework, or more subtle such as assigning more systems engineers to reduce a back-log of discrepancy reports from testing or to work off requests for action from design reviews. Unrealistic or flawed productivity assumptions for software development on the front-end of the planning process could be a factor driving schedule and cost, while too many unnecessary management reviews distracting the team on the back end of project execution could be another. Lack of robust schedule risk analysis could result in overlooking not only the impact of discrete risk events on the schedule, but also the effect of merge bias and insufficient margin levels. Even restrictions on travel, lack of discipline in schedule management, and resource conflicts or shortfalls can impact or influence both schedule and cost.

Continuing to maintain an awareness of the challenges associated with schedule delays and cost overruns among projects teams on complex projects is a vital and necessary step in reducing the likelihood and consequences of problems in the future. Logical steps that organizations can take to foster this awareness include:

- Conduct pause and learn workshops or after action reviews to analyze the reasons and implications for significant schedule delays and cost overruns on projects when significant adverse events occur.

- Implement standardized program planning and control practices that are repeatable and that the entire organization can use.

- Evolve cost basis of estimates (BOEs) into more integrated BOEs that incorporate a robust schedule component, particularly schedule assumptions if specific conditions are unknown at estimate time. 
- Encourage more widespread use of probabilistic schedule risk analysis to cross check schedule margin level adequacy and better understand risk priorities.

- Formulate a complexity index for the project or the schedule that would provide further insight into potential schedule volatility. Growth in task dependencies within the IMS might be a suitable starting point for such an index.

- Simplify or streamline techniques for calculating earned value on small scale projects. (GSFC developed a handbook for earned value determination for small projects and Class D missions as part of the BCI.)

- Devise a basic approach to contingency planning to more effectively respond to potentially catastrophic risks. Areas of focus would include alerting the project team, establishing safety procedures for travelers, or initiating additional safeguards and recovery of electronic data.
- Implement more robust internal programmatic assessments that augment routine status-oriented project reviews. Executive leadership simply cannot absorb all of the programmatic data for all projects. Proper programmatic analysis can independently evaluate project performance and provide helpful feedback and recommendations to both project and executive leadership.

Table 3 summarizes these approaches and associated impacts and outcomes. Both schedule and cost will always matter on projects, especially complex projects like those at NASA GSFC. Cost and schedule are two sides of the same coin, and schedule-driven cost growth is a serious concern. On complex projects, while the relationship between the two can be direct and obvious, other times it is more subtle and not so obvious. But for most projects, most of the time, project practitioners can agree that time is money. Put another way, as the schedule goes, so goes the cost.

Table 3. Recommendations for Enhancing Cost/Schedule Insight

\begin{tabular}{|c|c|c|}
\hline $\begin{array}{l}\text { Recommendations for Enhancing } \\
\text { Cost/Schedule Insight }\end{array}$ & $\begin{array}{c}\text { Affected Project Management } \\
\text { Processes }\end{array}$ & Impact/Outcome \\
\hline $\begin{array}{l}\text { Pause \& Learn Workshops (after a } \\
\text { major cost/schedule impact event) }\end{array}$ & Lessons learned/knowledge sharing & Inform other projects \\
\hline $\begin{array}{l}\text { Development of standard Project } \\
\text { Planning and Control processes and } \\
\text { practices }\end{array}$ & $\begin{array}{l}\text { Scheduling, EVM, cost estimating, risk } \\
\text { management, resource management }\end{array}$ & $\begin{array}{l}\text { Process repeatability across the } \\
\text { enterprise }\end{array}$ \\
\hline Integrated BOEs (cost and schedule) & Cost and schedule estimating & $\begin{array}{l}\text { More accurate cost and schedule } \\
\text { estimates }\end{array}$ \\
\hline Probabilistic risk analysis & $\begin{array}{l}\text { Risk management; schedule margin } \\
\text { planning; risk-informed decision } \\
\text { making }\end{array}$ & $\begin{array}{l}\text { Robust margins; counter merge bias; } \\
\text { better decisions }\end{array}$ \\
\hline Project complexity index & $\begin{array}{l}\text { Risk management; schedule margin } \\
\text { planning; risk-informed decision } \\
\text { making }\end{array}$ & $\begin{array}{l}\text { Robust margins; counter merge bias; } \\
\text { better decisions }\end{array}$ \\
\hline $\begin{array}{l}\text { Streamlined EVM techniques for small } \\
\text { projects }\end{array}$ & EVM, management reporting & $\begin{array}{l}\text { Integration of cost and schedule; } \\
\text { better project performance } \\
\text { accountability }\end{array}$ \\
\hline Project contingency planning & Risk management & $\begin{array}{l}\text { Improved reaction to "black swan" } \\
\text { events (i.e., safety, data back-up, } \\
\text { asset protection, team } \\
\text { communications) }\end{array}$ \\
\hline Internal programmatic assessments & Risk-informed decision making & $\begin{array}{l}\text { Better project performance } \\
\text { accountability; better decisions }\end{array}$ \\
\hline
\end{tabular}




\section{REFERENCES}

[1] S. Trail, "Focusing on Cost Is Not the Answer;" National Defense, National Defense Industrial Association, Arlington, VA, June 2015.

[2] J. Castaneda, T. Doolen, R. Malak, I. Tumer, R. Yim, "Exploring the Relationship Between Rework Projects and Risk Indicators," Project Management Journal, Project Management Institute, Newtown Square, PA, August/September 2015.

[3] D. Hulett, "Practical Schedule Risk Analysis," Gower Publishing Company, Surrey, United Kingdom, July 2009.

[4] "NOAA N-Prime Mishap Investigation Final Report," NASA, September 13, 2004.

[5] M. Cole, "Innovative Scheduling Analysis-Schedule Impact Analysis," presented at the 2012 NASA PM Challenge Conference, Orlando, FL, February 22-23, 2012.

[6] R. E. Bitten, D. L. Emmons, C. W. Freaner, "Conceptual Design Optimism, Cost and Schedule Growth Effects," presented at the 2010 NASA PM Challenge Conference, Galveston, TX, February 9-10, 2010.

[7] Email from R. E. Bitten to W. Majerowicz, dated January 11, 2015.

[8] R. E. Bitten, "Perspective on NASA Mission Cost and Schedule Performance Trends," 2008 Future In-Space Operations (FISO) Colloquium, Arizona State University, Tempe, AZ, July 2, 2008.

[9] Wikipedia, Root Cause, September 22, 2015.

[10] I. Bembers, M. Jones, E. Knox, J. Traczyk, "Better EVMS Implementation Themes and Recommendations," Joint Space Cost Council Themes and Recommendations, April 15, 2015.

[11] Office of Inspector General, Report No. IG-12-021, NASA's Challenges to Meeting Cost, Schedule, and Performance Goals, September 27, 2012.

[12] C. Caddell, J. Valdahl, "Understanding Merge Bias in Schedule Risk Analysis," AACE International Transactions, AACE International, Morgantown, WV, June 2010.

\section{BIOGRAPHY}

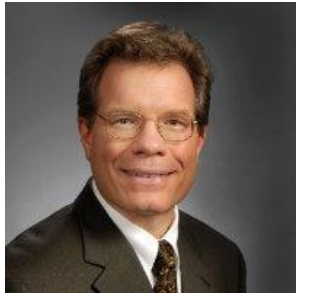

Walt Majerowicz provides scheduling, earned value management, and risk analysis support and training, currently serving as planning and scheduling subject matter expert at NASA's Goddard Spaceflight Center. Previously, he supported numerous programs and projects for NASA as planning and schedule manager, and provided independent programmatic analysis and integrated cost/schedule risk analysis support to NASA's Independent Program Assessment Office. Mr. Majerowicz also provided earned value management policy support to the Agency's Office of Chief Engineer, co-chaired the annual NASA Project Management Challenge conference, and was an instructor with the NASA Academy of Program, Project and Engineering Leadership (APPEL). He is an Adjunct Lecturer with Georgetown University, and is also a member of the National Ecological Observatory Network Project Advisory Committee. Major award and honors include NASA's Goddard Outstanding Mentor Award, NASA 's Public Service Medal, the Project Management Institute Distinguished Contribution Award, and NASA's Exceptional Public Achievement Medal.

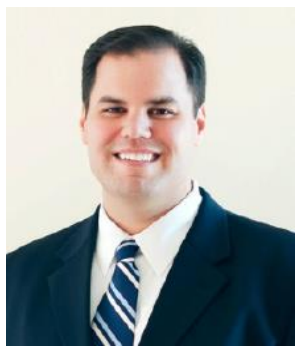

Steve Shinn is the Deputy Director for Planning and Business Management for the Flight Projects Directorate at NASA Goddard Space Flight Center. In this role, he serves as the principal operating official for the directorate in planning and developing management processes and business strategies. Mr. Shinn manages all matters related to business, project planning and control, resource management, organizational staffing, workforce development, diversity and equal opportunity, and physical assets. He is also an instructor in project planning and control at The Johns Hopkins University Whiting School of Engineering. Mr. Shinn was awarded NASA's Agency Honor Award and Robert H. Goddard Award for Leadership for his efforts in leading business change. He was also awarded NASA's Cost Estimating Award for Leadership and has received two team awards for Quality and Process Improvement for initiatives he championed and led for business change and risk analysis. 